\title{
Letter from . . . Sweden
}

\section{$2 \mathrm{~B}$ or not $\mathbf{2 B}-$ is that the question?}

\author{
D L FREEDMAN
}

In any Swedish restaurant you may see wine and spirits rolling along like old man river but don't be fooled, it's a 10:1 bet that the drinkers are not paying the bill. In fact, no Swede in his right mind would go to a restaurant to drink, the costs are astronomical. Liberal tax laws allow extensive deduction from company earnings for what is called "representation" so that most of the booze is a gift from the exchequer, who can then regain their losses from the high spirit tax.

\section{Glögg and Santa Lucia}

Glögg, the delicious traditional drink of the festive season, is a sweet red wine hot-toddy laced with spices and containing raisins and almonds. Its alcohol content varies from that of claret to the homemade considerably stronger varieties, and of course a totally alcohol-free type is available for the less festive. The glögg season is launched each 13 December-Santa Lucia or the festival of lights. For some obscure reason Swedes remember the auto-da-fé of this lesser known saint by prancing in a candle crown and a long white nightgown adorned with a scarlet sash. Festivities start at midnight on 12 December, and many a Nobel prize winner has been startled out of his wits when awoken at 5 am by these apparitions inviting their guests, with the strains of a well-known Neopolitan folksong, to nothing more alarming than a glass of hot glögg and a gingerbread man. Far more serious is the orgy of drunkenness that occurs all too often among school children under the guise of this harmless and picturesque tradition. Some schools no longer open on 13 December as teachers have suffered abuse and even bodily assault. Statistics show that $57 \%$ of 12 - and 13-year-old school children have tasted alcohol, while almost $10 \%$ of boys (somewhat fewer girls) drink regularly at this early age.

In a land where everything to do with alcohol is not a polite topic for conversation, so that even one glass of Châteauneufdu-Pape results in a guilty conscience, and if you drive home perhaps even a spell in gaol, $90 \%$ of the population drink, and more than $10 \%$ have a problem. Although drunkenness is no longer an offence in Sweden, being under the influence in command of a motor vehicle is, and a serious one. Swedish traffic laws recognise two degrees, mild insobriety (a blood alcohol concentration of $0.5-1.5 \mathrm{~g} / \mathrm{l}$ ) and rank inebriation (over $1.5 \mathrm{~g} / \mathrm{l})$. The former may result in a heavy fine and a withdrawn driving licence for some 12 months, whereas somebody in the latter state almost always receives a prison sentence of one to three months as well as a withdrawn licence, sometimes permanently. The sentence may however be served at a time convenient to the convicted in one of the special penal establishments mainly located in Sweden's "Siberia." In 1977 the 5723 con-

Jakobsbergs Sjukhus, Stockholm, Sweden

D L FREEDMAN, MB, LEGLAK, consultant surgeon victions for rank inebriation (over $1.5 \mathrm{~g} / \mathrm{l}$ ) while in charge of a motor vehicle included 759 foreign visitors.

\section{Drinking at home}

There are four ways of obtaining alcoholic beverages for home use.

Do it yourself-which includes rapid wine-making kits readily available from most supermarkets, but the only similarity of the final product to wine is alcohol content. Traditional winemaking from fruit, mainly apple and plums, is widely practised, sometimes with remarkably good results. Home distillation is illegal but many have an apparatus in the cellar to be activated, using sugar and yeast, on festive occasions. Home production of dandelion and nettle wine has recently been outlawed.

By smuggling - a concession of 1 litre of spirits and 1 litre of wine after an absence of not less than 24 hours is permitted. Custom control at Sweden's long borders-by land from Norway and by sea from Finland, Denmark, and Poland is fairly lax, and many risk taking a few extra bottles. Special boat trips from the Stockholm area to a group of Finnish islands in the Baltic sea (Åland) are popular. Ostensibly for sea air and good food, the primary reason for many is to obtain a supply of tax-free spirit. The profit from sales is such that travel costs are ridiculously low, but the level of inebriation on board will deter all but the most hardened.

Through a spirit shop (Systembolaget) which isn't always easy. Private enterprise is forbidden, and all spirit shops are owned, supplied, and run by the State. They are characterised by a magnificent window display of exotic non-alcoholic beverages, colourful anti-drinking posters, and are sparcely distributed throughout the country so that your town may not have one. When this happens the sale of spirits, wines, or strong beer (class 3 ) is through a locally appointed distributor, often the town postmaster. For an impulsive purchase you may have to travel 50 or 60 miles to the nearest State shop. Opening hours are restricted and prices are high, but there is an adequate assortment. Blended whisky costs about $£ 10$ for 0.751 , while an excellent bottle of French wine may be bought for $£ 2.50$. Beer is available in three classes called 1,2 , and 3 to denote increasing alcohol content. The strongest (3) can be bought at the spirit shop at about $50 \mathrm{p}$ a small bottle.

Besides wine kits, class 1 and 2 beer in cans or bottles are on sale at the supermarkets. Selling the stronger type (2) on Sundays and public holidays is, however, considered inappropriate.

It is this class 2 beer that has caused such disagreement and debate throughout the country over the past few years. Previously it was available in two strengths-a middle European Pilsner beer called " $2 \mathrm{~A}$ " and a somewhat stronger English lager type called " 2 B." Sweden, like most other industrial nations, has been concerned about the increasing consumption of alcohol, especially among its youth. Some attempted to draw a parallel between this and the increasing sales of readily available $2 \mathrm{~B}$ 
beer, and a movement was started for its abolition. Almost the whole country was divided on the issue, but eventually the small but powerful anti-alcohol parliamentary faction won, and $2 \mathrm{~B}$ was banned. Did this decrease alcoholism? Of course not: drinking habits were altered and $2 \mathrm{~B}$ abusers turned to cheap wines, whereas the rest of the population had to be satisfied with the rather tasteless $2 \mathrm{~A}$ or 2 as it is now called.

\section{Joys of the bottle}

What of the future ? To understand the present abolitionists' demands, I must briefly recount Sweden's drinking past.

It seems that Swedes from the Vikings onwards have always delighted in the joys of the bottle. In the early years of the century authorities were so alarmed by widespread alcoholism that a nationwide referendum was held as to whether alcohol should be forbidden. Those against prohibition won, but by such a narrow margin that a compromise, deemed expedient, resulted in a law severely restricting the sale of all alcoholic drinks. The adult population was issued with a "ration card" (Motbok), which permitted limited monthly amounts of spirits and wine to be bought and recorded at the State shops. Women were allowed less than men, and white collar workers more than labourers. Strong beer was at this time available only from the chemist on production of a doctor's prescription. Limited amounts of spirits and wines were served in restaurants with a meal, but never alone. Although State-employed spirit spies disguised as alcoholics were used to supervise enforcement, a free meal could be obtained by "donating" your drinks to a bypassing benefactor. These restrictions were abandoned in 1955.

Well, as can be expected, the cry is now "back to the Motbok," although possibly in a somewhat different guise to pacify the exponents of Women's Lib. Abolitionists, although only a tiny minority of the population are politically powerful (about onethird parliamentary members) and having successfully banned $2 \mathrm{~B}$ beer, without any drastic improvement in national spirit consumption, now believe that the alcohol problem can be solved by further partial or total prohibition.

Bootleggers rejoice-salvation is at hand!

\title{
Scientifically Speaking
}

\section{Assessing the benefits}

\author{
BARBARA J CULLITON, WALLACE K WATERFALL
}

Washington DC-These days no research into new treatments for disease seems to be getting as much emphasis as that into old treatments to find out how well they work. Much encouragement for studies of the effectiveness of established treatments, at least in the United States, comes from the federal government, which pays for an increasing number of treatments and pays an increasing cost for most of them.

The principal method of making an acceptable test of therapeutic effectiveness is still the prospective, randomised, controlled clinical trial. Because there are very few ills today for which no old favourite remedy exists, clinical trials usually pit a promising new treatment against an entrenched older one; placebos are less often feasible. And, if the shade of difference between the effectiveness of two treatments is small enough, beating the $0.05 \mathrm{p}$ value requires a staggeringly large enrolment of patients in the study. Several questions have popped up recently about the applicability of the randomised, controlled trial, and even about its objectivity. ${ }^{1}$ But increasingly it is invoked to settle medical matters that could upset the public health or purse.

A recent success of such a trial was achieved by an immense investigation that apparently proves the worth of treating borderline hypertensives, which we'll get to in a moment. But one of the biggest challenges ever to the art of effectiveness

5026 Eskridge Terrace NW, Washington DC 20016, USA

BARBARA J CULLITON, AB, news editor of Science, the weekly journal of the American Association for the Advancement of Science

WALLACE $\mathrm{K}$ WATERFALL, $\mathrm{AB}$, senior professional associate and director, Office of Communications, Institute of Medicine, National Academy of Sciences testing is shaping up now in murmurings in both Congress and a major federal health agency. The question: how worth while are treatments for mental disorders?

\section{Treatment for medical disorders}

More and more legislative proposals in Congress would expand government payment policies for psychotherapies. Care for mental illness under most federal programmes has more constraints on payment than care for physical illness does. And, although government still pays slightly less than half of the American bills for health care, many private health insurance plans follow the government's lead as to what ills, what treatments, and even what kind of healers will be taken care of by insurance payments.

Last autumn the head of the government's mental health agency asked his advisers to come up with ideas for clinical research that could assess the worth of psychotherapies. Without proof of effectiveness, he suggested, not only might mental health treatment be neglected in bigger health insurance programmes, but it might also be cut out of any coverage. A short time earlier the appropriate congressional subcommittee, whose purview includes legislation that determines what kinds of sickness care the government will pay for, let it be known that there should be a feeling of urgency about studies of psychotherapeutic effectiveness. It appears, wrote the subcommittee's staff chief, that "there are virtually no controlled clinical studies, conducted and evaluated in accordance with generally accepted scientific principles, which confirm the efficacy, safety, and appropriateness of psychotherapy as it is conducted today."

That is true, as far as it goes, but it tends to discount the knowledge that has been amassed by uncounted clinicians and 